\title{
Comparative analysis of stress distribution around CFR-PEEK implants and titanium implants with different prosthetic crowns: A finite element analysis
}

\author{
Swapnil Kumar Tamrakar, ${ }^{1, A-F}$, Sunil Kumar Mishra ${ }^{2, A-F}$, Ramesh Chowdhary ${ }^{3, A-F}$, Srinivas Ra0 $0^{4, A-F}$ \\ ${ }^{1}$ Galaxy Dental Clinic and Implant Centre, Udaipur, India \\ 2 Department of Prosthodontics, Rama Dental College, Hospital \& Research Centre, Kanpur, India \\ ${ }^{3}$ Department of Prosthodontics, Rajarajeswari Dental College \& Hospital, Bengaluru, India \\ ${ }^{4}$ Department of Prosthodontics, Gitam Dental College \& Hospital, Visakhapatnam, India \\ A - research concept and design; $\mathrm{B}$ - collection and/or assembly of data; $\mathrm{C}$ - data analysis and interpretation; \\ $\mathrm{D}$ - writing the article; $\mathrm{E}$ - critical revision of the article; $\mathrm{F}$ - final approval of the article
}

Address for correspondence

Sunil Kumar Mishra

E-mail: sunilmsr200@yahoo.co.in

Funding sources

None declared

Conflict of interest

None declared

Received on December 13,2020

Reviewed on February 9,2021

Accepted on February 11, 2021

Published online on September 30, 2021

Cite as

Tamrakar SK, Mishra SK, Chowdhary R, Rao S. Comparative analysis of stress distribution around CFR-PEEK implants and titanium implants with different prosthetic crowns: A finite element analysis. Dent Med Probl. 2021;58(3):359-367. doi:10.17219/dmp/133234

DOI

$10.17219 / \mathrm{dmp} / 133234$

Copyright

○ 2021 by Wroclaw Medical University

This is an article distributed under the terms of the

Creative Commons Attribution 3.0 Unported License (CC BY 3.0)

(https://creativecommons.org/licenses/by/3.0/).

\begin{abstract}
Background. Polyetheretherketone (PEEK) is a new material that was introduced for the fabrication of implants and their superstructure along with other available materials. It is not yet known whether the carbon fiber-reinforced polyetheretherketone (CFR-PEEK) material can be used as an implant and its superstructure in place of titanium (Ti).

Objectives. The study evaluated stress distribution around CFR-PEEK implants and Ti implants with 5 different prosthetic crowns.
\end{abstract}

Material and methods. A three-dimensional (3D) model of a bone block was created to represent the right maxillary premolar area with a bone-level implant system with $100 \%$ osseointegration, using the Ansys Workbench software, v. 15.0. In total, $103 \mathrm{D}$ finite element analysis (FEA) models were created. The models were divided into 2 groups according to the type of implant: the CFR-PEEK group $(n=5)$; and the Ti group $(n=5)$. Each group was subdivided to imitate 5 different restorative crown materials (PEEK, zirconia, porcelain fused to metal (PFM), metal, and acrylic resin). Each implant model was loaded vertically (200 N) and obliquely (100 N). Stress distribution in the implants, the abutments, the cement layers, and the crowns was evaluated using the von Mises stress analysis. Maximum and minimum principal stress analyses were used to determine the stress generated in the bone.

Results. The CFR-PEEK implants bore more stress in vertical and oblique loading as compared to the Ti implants. The stress generated in the bone with the CFR-PEEK implants was similar to that generated with the Ti implants under vertical loading. Under oblique loading, less stress was transferred to the bone with the CFR-PEEK implants as compared to the Ti implants, showing better adaptation of the CFR-PEEK implants to lateral stress.

Conclusions. In this FEA study, the amount of stress generated within the bone in the case of the CFR-PEEK implants with different restorative crowns was smaller in comparison with the Ti implants in oblique loading. This could help reduce lateral stress on implants as well as crestal bone loss.

Keywords: dental implant, finite element analysis, polyetheretherketone, titanium, zirconium oxide 


\section{Introduction}

Dental implant-supported prostheses are becoming the preferred treatment option in dentistry to replace missing teeth due to their long-term survivability and proven advantages. ${ }^{1,2}$ The pattern of stress distribution during mastication differs in implants, as the forces are directly transferred to the adjacent surrounding bone, which plays a vital role in the success of implants. ${ }^{3,4}$ The lack of the periodontal ligament in dental implants causes decreased proprioception at the implant-bone interface. This decreased resilience results in increased forces, which often leads to implant failure and chipping of dental porcelain. ${ }^{5,6}$

Titanium (Ti) is the material of choice for dental implants; it was introduced by Brånemark in 1978. ${ }^{7}$ However, certain drawbacks with regard to the use of Ti have been reported in the literature, such as its tendency to cause hypersensitivity and allergic reactions. ${ }^{8-10}$ Another drawback is that its modulus of elasticity differs from that of the surrounding bone. This causes stress concentration at the implant-bone interface during load transfer, resulting in peri-implant bone loss. ${ }^{11}$ Titanium also evokes scattering rays when it is in the field of radiation, which is harmful to tissues. ${ }^{12}$

In the last few years, ceramics, mainly yttria-stabilized tetragonal zirconia polycrystalline, have been used as an alternative to Ti implants. They have favorable properties, such as translucency and white color that simulate natural teeth. However, the promotion of ceramic implants to satisfy increasing esthetic demands is fraught with compromise due to the brittle nature of zirconia materials. This significant susceptibility to surface defects can increase stress concentration at these sites. ${ }^{13,14}$

More recently, polyetheretherketone (PEEK) has become a source of research interest and is being tested for use as an implant material. ${ }^{15}$ Polyetheretherketone is a synthetic, polymeric, organic material, developed in 1978, that is characterized by good chemical resistance, good mechanical properties and biocompatibility. Polyetheretherketone is compatible with modern imaging technologies. It is a tooth-colored material that has recently been used as a dental implant material when esthetics is a major concern. Polyetheretherketone is being used for the implant superstructure, the abutment, implant fixture, and implant-supported hybrid prostheses. The Young's modulus of the PEEK material in its pure form is 3.6 GPa, of carbon fiber-reinforced PEEK (CFR-PEEK) around $18 \mathrm{GPa}$ and of glass fiber-reinforced PEEK 12 GPa. ${ }^{16,17}$ The CFR-PEEK material is a biologically inert material. Studies on cytotoxicity, mutagenicity, carcinogenicity, and immune system impairment have found no evidence that it has any harmful effects. ${ }^{18-20}$

The success of an implant depends on the type of material used for the implant superstructure. Many materials are being used today for implant prostheses, such as porcelain fused to metal (PFM) crowns, all-ceramic crowns, full-cast crowns, and acrylic resin crowns, with each having its own limitations. ${ }^{21}$ The Young's modulus of CFR-PEEK is close to that of the cortical bone; hence, it exhibits less stress shielding than Ti. However, not much is known about the use of CFR-PEEK as a dental implant and its superstructure. ${ }^{22,23}$ Thus, this study attempted to use the finite element analysis (FEA) to determine the stress generated by this new material on the implant and its adjacent surrounding bone.

The aim of this study was to use FEA to evaluate stress distribution around CFR-PEEK implants and Ti implants with 5 types of prosthetic crowns (PEEK, zirconia, PFM, metal, and acrylic resin) under vertical and oblique loading. The null hypothesis was that there would be no differences in the distribution of stress around CFR-PEEK and Ti implants with different prosthetic crowns.

\section{Material and methods}

This experimental study was conducted in the principal author's institution in collaboration with CADD Solutions, Vijayawada, India. The FEA model was generated carefully so that it resembled the real object to ensure an effective and accurate analysis. ${ }^{24}$

\section{Model generation}

An edentulous maxilla was scanned using a dental volumetric computed tomography (CT) device (the HDI 100 Series 3D scanner with the FlexScan3D software; LMI Technologies, Burnaby, Canada). A model was generated to simulate the right maxillary premolar zone with a cancellous bone thickness of $2 \mathrm{~cm}$, surrounded by a 1.5 -millimeter-thick cortical bone. The bones were given different colors so that they could be easily identified. The properties of the components generated in the model were kept isotropic, linear and homogeneous. ${ }^{5}$ Movement in the $\mathrm{X}, \mathrm{Y}$ and $\mathrm{Z}$ planes of the bone surface was prevented by keeping the boundary conditions fixed at the alveolar bone level. ${ }^{25}$ The effect of the gingiva on the implant during loading seemed to be negligible, so it was not modeled in the generated model. ${ }^{5,26}$

A Ti implant $(\varnothing 4.1 \mathrm{~mm} \times 10 \mathrm{~mm})\left(\right.$ Straumann $^{\circledR}$ Bone Level Implants; Straumann USA, Andover, USA) with a Ti abutment $(\varnothing 4.5 \mathrm{~mm} \times 4 \mathrm{~mm})$ (Straumann CrossFit ${ }^{\circledR}$ Abutments; Straumann USA) and a Ti screw was scanned with the HDI 100 series 3D scanner. The Standard Tessellation Language (STL) data obtained for each scanned component was transferred into 3D modeling software (Ansys Workbench, v. 15.0; Ansys Inc., Canonsburg, USA). The 3D model of the implant was considered to be $100 \%$ osseointegrated in the bone. ${ }^{5,22}$

In total, 10 3D FEA models were created. The FEA models were divided into 2 main groups based on the type of implant - the CFR-PEEK group implants $(n=5)$ were 
given the properties of CFR-PEEK implants and abutments, while the Ti group implants $(n=5)$ were given the properties of Ti implants and abutments. The abutment was placed over the implant in proper adaptation, followed by modeling of the restorative crowns. Each group was subdivided to imitate 5 restorative crown materials (PEEK, zirconia, PFM, metal, and acrylic resin). The restorative PFM crown was modeled with a metal thickness of the coping of $0.5 \mathrm{~mm}$ and a porcelain thickness of at least $1.5 \mathrm{~mm}$ in the occlusal area of the functional cusp. Similar dimensions of the PEEK crown with a PEEK thickness of the coping of $0.5 \mathrm{~mm}$, layered with a microhybrid composite (Ceramage ${ }^{\circledR}$; Shofu, Inc., Kyoto, Japan) thickness of at least $1.5 \mathrm{~mm}$ in the occlusal area of the functional cusp were modeled. The crown thickness for zirconia and acrylic resin was $2 \mathrm{~mm}$, while it was $1.5 \mathrm{~mm}$ for the metal crown in the occlusal area of the functional cusp. ${ }^{27}$ A 30-micrometer-thick layer of dual-polymerized resin cement (Panavia ${ }^{\mathrm{TM}}$ F 2.0; Kuraray Europe, Hattersheim am Main, Germany) was also created between the crown and the abutment to exactly simulate clinical conditions. ${ }^{5,28}$

\section{Setting material properties}

The Young's modulus and Poisson's ratio of the various materials were obtained from the published research and installed into the software (Table 1). ${ }^{29-35}$

\section{Load and constraints}

All 10 models were tested in terms of stress distribution with $200 \mathrm{~N}$ of vertical load applied to the central fossa and $100 \mathrm{~N}$ of oblique load at an angle of $30^{\circ}$ applied to the buccal incline of the palatal cusp (Fig. 1A)..$^{5,36}$

Table 1. Young's modulus and Poisson's ratio of each material

\begin{tabular}{|l|c|c|}
\multicolumn{1}{c}{ Material/Structure } & $\begin{array}{c}\text { Young's modulus } \\
{[\mathrm{GPa}]}\end{array}$ & Poisson's ratio \\
\hline Cortical bone & $13.70^{29}$ & $0.30^{29}$ \\
Cancellous bone & $1.37^{29}$ & $0.30^{29}$ \\
\hline Ti implant, abutment, screw & $110.00^{29}$ & $0.35^{29}$ \\
CFR-PEEK implant, abutment & $150.00^{30}$ & $0.39^{*}$ \\
Porcelain & $69.00^{31}$ & $0.30^{31}$ \\
Zirconia & $210.00^{32}$ & $0.30^{32}$ \\
Composite & $10.70^{*}$ & $0.30^{*}$ \\
Acrylic resin & $3.00^{33}$ & $0.30^{33}$ \\
PEEK & $4.10^{*}$ & $0.40^{*}$ \\
Ni-Cr & $203.60^{34}$ & $0.30^{34}$ \\
Co-Cr & $218.00^{29}$ & $0.33^{29}$ \\
Dual-polymerized resin cement & $18.60^{35}$ & $0.28^{35}$ \\
\hline
\end{tabular}

Ti - titanium; CFR-PEEK - carbon fiber-reinforced polyetheretherketone; PEEK - polyetheretherketone; $\mathrm{Ni}$ - nickel; $\mathrm{Cr}$ - chromium; Co - cobalt;

* values provided by the manufacturer.

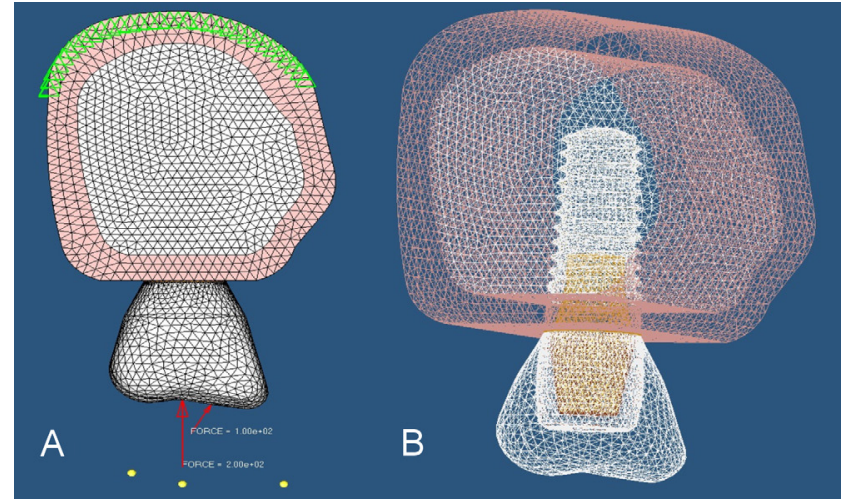

Fig. 1. A - model showing $200 \mathrm{~N}$ of vertical load applied to the central fossa and $100 \mathrm{~N}$ of oblique load at an angle of $30^{\circ}$ applied to the buccal incline of the palatal cusp; B - mesh-generated model

\section{Meshing and contact characteristics}

The mesh refinement level was limited by converting the mesh with a controlled and connected element corresponding to each structure (Fig. 1B). Meshing was applied to divide the model into nodes and elements, with 233,750 nodes and 167,348 elements generated in this study. ${ }^{37}$ Stress distribution in the implants, the abutments, the cement layers, and the restorative crowns was evaluated using the von Mises stress analysis. Maximum and minimum principal stress analyses were used to determine the stress generated in the bone. The von Mises stress analysis was used to determine the effect of the loading forces on the implant and the restorative structures. The generated stress was measured in megapascals $(\mathrm{MPa})$; it provided information about the point where the elastic boundary was exceeded. The comparison among the different models was performed with the help of a color scale representing the levels of the generated stress in different colors.

\section{Results}

The forces were applied in 2 directions in each model. The values of von Mises stress as well as of maximum and minimum stress were evaluated for each model; they are presented in Tables 2-6.

The maximum and minimum principal stress values within the bone for the CFR-PEEK and Ti implants with different restorative crowns are shown in Table 2 . In vertical loading, the maximum principal stress generated in the bone with the CFR-PEEK implants and the PEEK crown $(5.888 \mathrm{MPa})$, the zirconia crown $(5.889 \mathrm{MPa})$, the PFM crown $(5.888 \mathrm{MPa})$, the metal crown $(5.889 \mathrm{MPa})$, and the acrylic resin crown $(5.888 \mathrm{MPa})$ was slightly greater as compared to the Ti implants and the PEEK crown (5.645 MPa), the zirconia crown (5.649 MPa), the PFM crown (5.645 MPa), the metal crown (5.649 MPa), and the acrylic resin crown $(5.648 \mathrm{MPa})$. Under oblique loading, there was less stress generated in the bone 
Table 2. Minimum and maximum principal stress values [MPa] observed in the bone under vertical and oblique loading

\begin{tabular}{|c|c|c|c|c|c|c|c|c|}
\hline \multirow{3}{*}{ Crown } & \multicolumn{4}{|c|}{ Vertical loading } & \multicolumn{4}{|c|}{ Oblique loading } \\
\hline & \multicolumn{2}{|c|}{ CFR-PEEK group } & \multicolumn{2}{|c|}{ Ti group } & \multicolumn{2}{|c|}{ CFR-PEEK group } & \multicolumn{2}{|c|}{ Ti group } \\
\hline & $\min$ & $\max$ & $\min$ & $\max$ & $\min$ & $\max$ & $\min$ & $\max$ \\
\hline PEEK & 0.654 & 5.888 & 0.627 & 5.645 & 0.928 & 8.357 & 1.039 & 9.354 \\
\hline Zirconia & 0.654 & 5.889 & 0.627 & 5.649 & 0.922 & 8.301 & 1.031 & 9.282 \\
\hline PFM & 0.654 & 5.888 & 0.627 & 5.645 & 0.925 & 8.333 & 1.037 & 9.330 \\
\hline Metal & 0.654 & 5.889 & 0.627 & 5.649 & 0.922 & 8.300 & 1.031 & 9.282 \\
\hline Acrylic resin & 0.654 & 5.888 & 0.627 & 5.648 & 0.924 & 8.323 & 1.034 & 9.309 \\
\hline
\end{tabular}

PFM - porcelain fused to metal.

for the CFR-PEEK implants with the the PEEK crown (8.357 $\mathrm{MPa})$, the zirconia crown $(8.301 \mathrm{MPa})$, the PFM crown $(8.333 \mathrm{MPa})$, the metal crown $(8.300 \mathrm{MPa})$, and the acrylic resin crown $(8.323 \mathrm{MPa})$ as compared to the Ti implants with the PEEK crown (9.354 MPa), the zirconia crown $(9.282 \mathrm{MPa})$, the PFM crown $(9.330 \mathrm{MPa})$, the metal crown $(9.282 \mathrm{MPa})$, and the acrylic resin crown (9.309 $\mathrm{MPa})$. The CFR-PEEK implant with the PEEK crown showed similar stress in vertical loading (Fig. 2A) and less stress in oblique loading (Fig. 2B) when compared with the Ti implant with the the PEEK crown (Fig. 2C and Fig. 2D). The stress was more concentrated at the crest region near the implant-abutment connection area in oblique loading for both

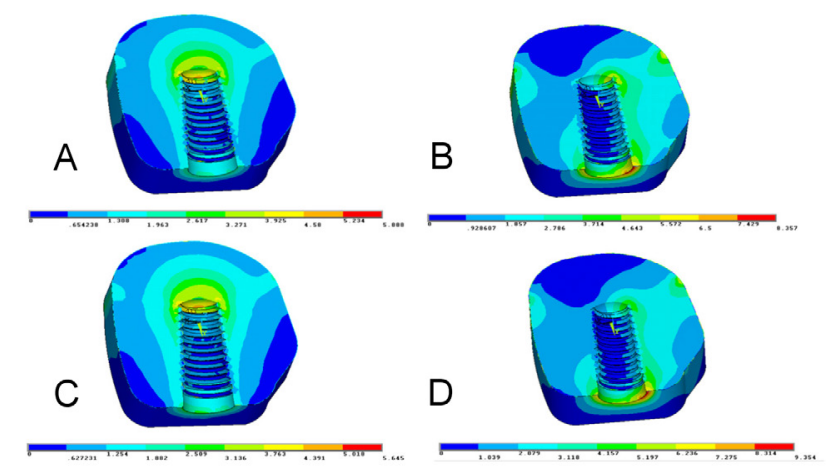

Fig. 2. A - stress generated in the bone in the model with the CFR-PEEK implant-abutment and the PEEK crown in vertical loading; B - stress generated in the bone in the model with the CFR-PEEK implant-abutment and the PEEK crown in oblique loading; $\mathrm{C}$ - stress generated in the bone in the model with the Ti implant-abutment and the PEEK crown in vertical loading; D - stress generated in the bone in the model with the Ti implant-abutment and the PEEK crown in oblique loading implant groups, but it was less concentrated in the CFR-PEEK implant group (Fig. 2B).

The von Mises stress values within the implant for the CFR-PEEK and Ti implants with different restorative crowns are listed in Table 3 . Under vertical and oblique loading, the stress generated in the implant was greater in the CFR-PEEK implant group with different restorative crowns as compared to the $\mathrm{Ti}$ implant group. Under vertical loading, the stress generated in the CFR-PEEK implants in comparison with the Ti implants with different restorative crowns was as follows: the PEEK crown - 221.859 MPa vs $195.693 \mathrm{MPa}$; the zirconia crown - 221.881 MPa vs $195.072 \mathrm{MPa}$; the PFM crown - 221.867 MPa vs 195.703 MPa; the metal crown 221.881 MPa vs 195.072 MPa; and the acrylic resin crown - 221.861 MPa vs 195.044 MPa. Under oblique loading, the stress generated in the CFR-PEEK implants in comparison with the $\mathrm{Ti}$ implants with different restorative crowns was as follows: the PEEK crown - 291.150 MPa vs $240.785 \mathrm{MPa}$; the zirconia crown - 291.098 $\mathrm{MPa}$ vs $240.433 \mathrm{MPa}$; the PFM crown - 291.090 MPa vs $240.718 \mathrm{MPa}$; the metal crown - $291.096 \mathrm{MPa}$ vs 240.430 MPa; and the acrylic resin crown $-291.164 \mathrm{MPa}$ vs $240.506 \mathrm{MPa}$. The CFR-PEEK implant with the PEEK crown showed more stress in vertical (Fig. 3A) and oblique loading (Fig. 3B) when compared with the Ti implant with the PEEK crown (Fig. 3C and Fig. 3D). Although in oblique loading, the stress was more concentrated at the crest and body of the implants in both implant groups, the result showed that the maximum stress generated was taken up by the CFR-PEEK implant in a better way as compared to the Ti implant (Fig. 3B).

Table 3. von Mises stress values [MPa] observed under vertical and oblique loading within the implant

\begin{tabular}{|c|c|c|c|c|}
\hline \multirow{2}{*}{ Crown } & \multicolumn{2}{|c|}{ Vertical loading } & \multicolumn{2}{|c|}{ Oblique loading } \\
\hline & CFR-PEEK group & Ti group & CFR-PEEK group & Ti group \\
\hline PEEK & 221.859 & 195.693 & 291.150 & 240.785 \\
\hline Zirconia & 221.881 & 195.072 & 291.098 & 240.433 \\
\hline PFM & 221.867 & 195.703 & 291.090 & 240.718 \\
\hline Metal & 221.881 & 195.072 & 291.096 & 240.430 \\
\hline Acrylic resin & 221.861 & 195.044 & 291.164 & 240.506 \\
\hline
\end{tabular}




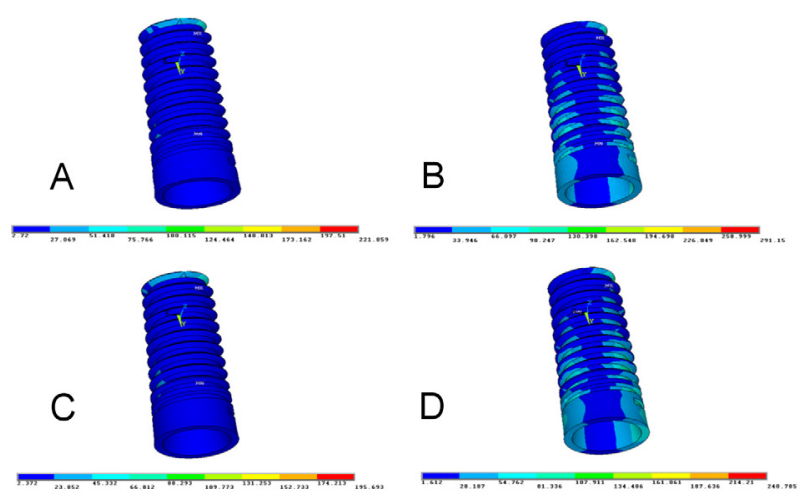

Fig. 3. A - stress generated within the implant in the model with the CFR-PEEK implant-abutment and the PEEK crown in vertical loading; B - stress generated within the implant in the model with the CFR-PEEK implant-abutment and the PEEK crown in oblique loading; $\mathrm{C}$ - stress generated within the implant in the model with the Ti implant-abutment and the PEEK crown in vertical loading; D - stress generated within the implant in the model with the Ti implantabutment and the PEEK crown in oblique loading

The von Mises stress values within the CFR-PEEK and Ti abutments with different restorative crowns are shown in Table 4. The stress generated in the abutment in vertical (84.572 MPa) (Fig. 4A) and oblique loading (101.613 MPa) (Fig. 4B) in the CFR-PEEK abutment with the PEEK crown was slightly greater than in the Ti abutment with the PEEK crown (77.933 $\mathrm{MPa}$ and 99.187 $\mathrm{MPa}$, respectively) (Fig. 4C and Fig. 4D). The stress generated in the CFR-PEEK abutments with the zirconia, PFM and metal crowns was lower under both vertical and oblique loading in comparison with similar crowns in the Ti implant group. The stress generated in the CFR-PEEK abutment with the acrylic resin crown was higher under both vertical and oblique loading in comparison with the same crown in the Ti implant group (Table 4). Under vertical and oblique loading, stress concentration was higher at the implant-abutment connection area.

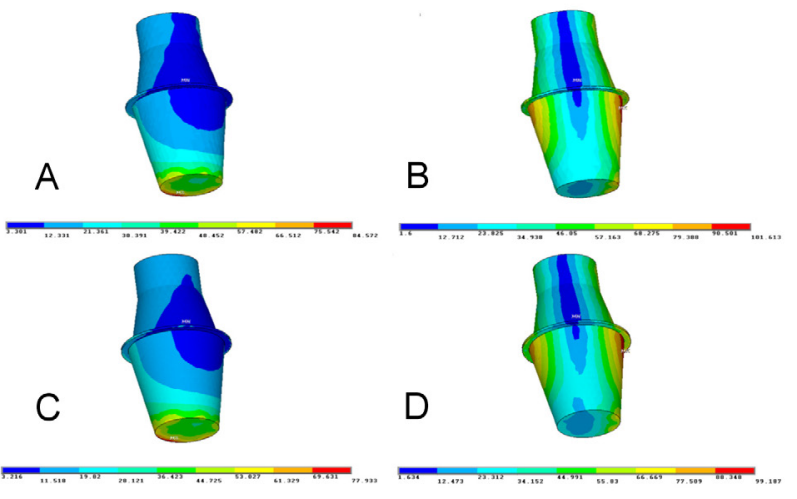

Fig. 4. A - stress generated in the CFR-PEEK abutment with the PEEK crown in vertical loading; $B$ - stress generated in the CFR-PEEK abutment with the PEEK crown in oblique loading; $\mathrm{C}$ - stress generated in the Ti abutment with the PEEK crown in vertical loading; D - stress generated in the Ti abutment with the PEEK crown in oblique loading

The von Mises stress values within the cement layer of the different restorative crowns cemented to the CFR-PEEK and $\mathrm{Ti}$ abutments are shown in Table 5. Among all of the restorative crowns, the highest stress generated in the cement layer for both types of loading (vertical and oblique) was with the acrylic resin crown. The stress generated in the cement layer in vertical (46.154 $\mathrm{MPa}$ ) (Fig. 5A) and oblique loading (49.750 MPa) (Fig. 5B) in the CFR-PEEK abutment with the PEEK crown was slightly greater as compared to the Ti abutment with the PEEK crown (44.160 MPa and $46.006 \mathrm{MPa}$, respectively) (Fig. 5C and Fig. 5D). The amount of stress generated in the cement layer with the CFR-PEEK abutments and the zirconia, PFM and metal crowns was smaller in oblique loading when compared with similar crowns in the Ti implant group (Table 5). The stress generated in vertical loading in both groups was more concentrated toward the occlusal aspect of the

Table 4. von Mises stress values [MPa] observed under vertical and oblique loading within the abutment

\begin{tabular}{|c|c|c|c|c|}
\hline \multirow{2}{*}{ Crown } & \multicolumn{2}{|c|}{ Vertical loading } & \multicolumn{2}{|c|}{ Oblique loading } \\
\hline & CFR-PEEK group & Ti group & CFR-PEEK group & Ti group \\
\hline PEEK & 84.572 & 77.933 & 101.613 & 99.187 \\
\hline Zirconia & 30.169 & 35.627 & 88.867 & 93.797 \\
\hline PFM & 32.304 & 38.824 & 90.307 & 105.947 \\
\hline Metal & 33.846 & 39.136 & 89.759 & 102.354 \\
\hline Acrylic resin & 109.180 & 103.525 & 120.672 & 111.805 \\
\hline
\end{tabular}

Table 5. von Mises stress values [MPa] observed under vertical and oblique loading within the cement layer

\begin{tabular}{|c|c|c|c|c|}
\hline \multirow{2}{*}{ Crown } & \multicolumn{2}{|c|}{ Vertical loading } & \multicolumn{2}{|c|}{ Oblique loading } \\
\hline & CFR-PEEK group & Ti group & CFR-PEEK group & Ti group \\
\hline PEEK & 46.154 & 44.160 & 49.750 & 46.006 \\
\hline Zirconia & 8.327 & 8.929 & 16.300 & 18.581 \\
\hline PFM & 9.439 & 8.745 & 16.420 & 18.785 \\
\hline Metal & 8.295 & 9.062 & 16.373 & 18.835 \\
\hline Acrylic resin & 59.870 & 59.212 & 69.521 & 67.610 \\
\hline
\end{tabular}




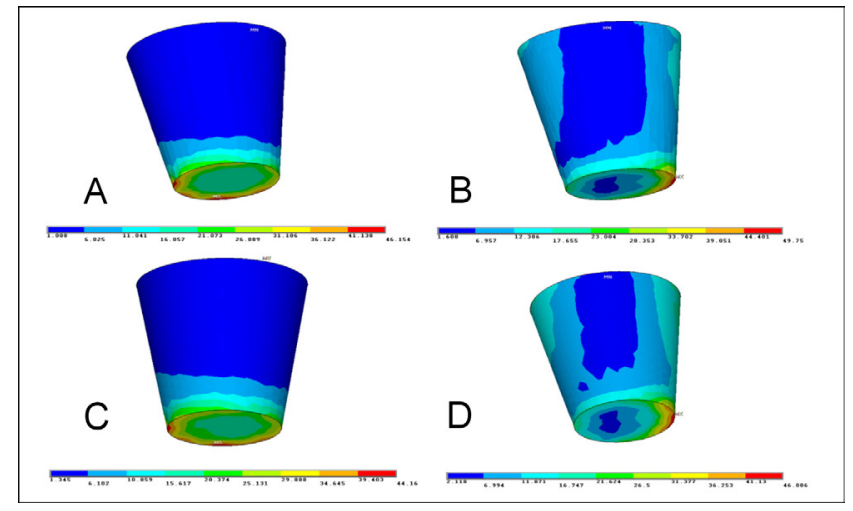

Fig. 5. A - stress generated in the cement layer of the model with the CFR-PEEK abutment and the PEEK crown in vertical loading; B - stress generated in the cement layer of the model with the CFR-PEEK abutment and the PEEK crown in oblique loading; C - stress generated in the cement layer of the model with the Ti abutment and the PEEK crown in vertical loading; D - stress generated in the cement layer of the model with the Ti abutment and the PEEK crown in oblique loading

cement layer, whereas in oblique loading, the stress was more concentrated toward the implant-abutment connection area.

The von Mises stress values within the different crowns cemented to the CFR-PEEK and $\mathrm{Ti}$ abutments are presented in Table 6. Under vertical and oblique loading, the stress generated in all of the crowns cemented to the CFR-PEEK abutment was similar to that generated in the crowns cemented to the Ti abutments. The stress generated in the PEEK crown cemented to the CFR-PEEK abutment (Fig. 6A and Fig. 6B) was observed to be similar to that generated in the PEEK crown cemented to the Ti abutment (Fig. 6C and Fig. 6D). Under vertical loading, the stress was more concentrated in the central fossa region of the crowns. Under oblique loading, the stress was more concentrated on the buccal inclines of the palatal cusps and at the margins of the crowns in both groups.

\section{Discussion}

This study analyzed the null hypothesis that no difference would be found in stress distribution around CFR-PEEK implants and $\mathrm{Ti}$ implants with 5 different prosthetic crowns. Based on the results of this study, the null hypothesis was rejected.

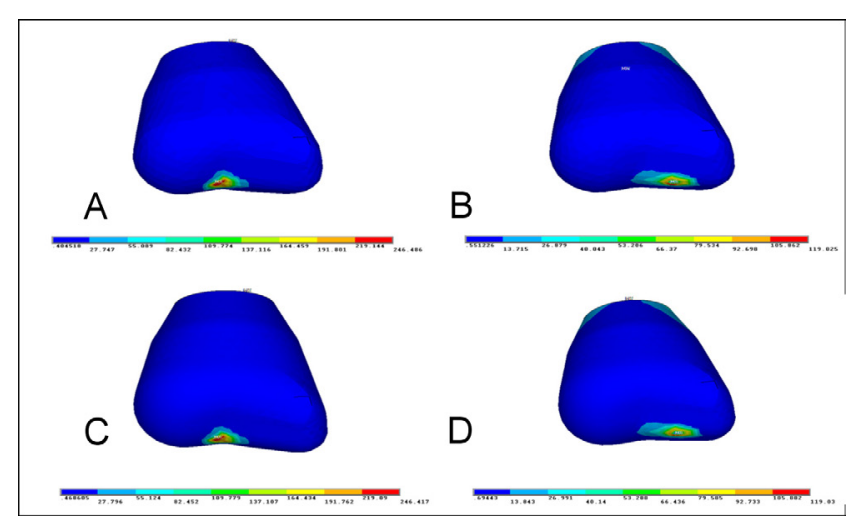

Fig. 6. A - stress generated in the PEEK crown cemented to the CFR-PEEK abutment in vertical loading; $B$ - stress generated in the PEEK crown cemented to the CFR-PEEK abutment in oblique loading; $\mathrm{C}$ - stress generated in the PEEK crown cemented to the Ti abutment in vertical loading; D - stress generated in the PEEK crown cemented to the Ti abutment in oblique loading

The finite element analysis is a suitable scientific method for assessing biomechanical behavior in complex configurations. The FEA models can be two-dimensional (2D) or 3D. In this study, 3D models were used to achieve true-to-life results. ${ }^{38}$ The failure of the material may occur if the von Mises stress values are greater than $550 \mathrm{MPa}$, which is the yield strength of $\mathrm{Ti}^{39}$ In this study, all the FEA models of the implants in both subgroups had von Mises stress values well below $550 \mathrm{MPa}$. Under oblique loading, the highest von Mises stress value was obtained with the CFR-PEEK implant (291 MPa).

Stress dissemination in the implant components, the peripheral bone and the restorative crowns was evaluated under vertical $(200 \mathrm{~N})$ and oblique loading (100 N). Continuous concentration of masticatory forces at a point on a dental implant for a long time may lead to implant failure. Taking that into consideration, in this study, the vertical load was applied to the central fossa so that it could be distributed to the palatal and buccal cusps, while the oblique load was applied to the functional palatal cusp. ${ }^{40}$

In this study, CFR-PEEK was used based on a growing interest in its application in implant dentistry due to its adaptability, affinity with present-day imaging technologies, outstanding mechanical properties, and biological acceptability. ${ }^{41}$ In this study, under vertical and oblique loading, the CFR-PEEK and $\mathrm{Ti}$ implant groups transferred forces in a homogeneous fashion with all restor-

Table 6. von Mises stress values [MPa] observed under vertical and oblique loading within the crown

\begin{tabular}{|c|c|c|c|c|}
\hline \multirow{2}{*}{ Crown } & \multicolumn{2}{|c|}{ Vertical loading } & \multicolumn{2}{|c|}{ Oblique loading } \\
\hline & CFR-PEEK group & Ti group & CFR-PEEK group & Ti group \\
\hline PEEK & 246.486 & 246.417 & 119.025 & 119.030 \\
\hline Zirconia & 257.298 & 257.169 & 123.861 & 123.864 \\
\hline PFM & 229.884 & 229.772 & 111.470 & 111.472 \\
\hline Metal & 245.768 & 245.637 & 119.019 & 119.022 \\
\hline Acrylic resin & 229.909 & 229.887 & 111.517 & 111.520 \\
\hline
\end{tabular}


ative crowns. Stress in both the CFR-PEEK and Ti implant groups was more concentrated at the implant-abutment connection area, which is consistent with other studies, and this was due to the rigid connection between the implant and the bone (Fig. 2B and Fig. 2D). ${ }^{5,16}$ Due to its increased modulus of elasticity in comparison with the spongy bone, the cortical bone is stronger and more resistant to deformation; the stress values in the prostheses and the peripheral bone increase in oblique loading. ${ }^{40}$ A similar result was obtained in the present study with both the CFR-PEEK and Ti implants (Fig. 2B and Fig. 2D).

Sarot et al. compared the stress distributed by $30 \%$ CFR-PEEK and $\mathrm{Ti}$ and found that a dental implant with endless carbon fibers can decrease elastic deformation and help decrease the stress peaks at the implant-bone interface $^{15}$ Bataineh and $\mathrm{Al}$ Janaideh ${ }^{41}$ found that the substitution of a PEEK implant for a Ti implant does not provide any advantages in regard to stress distribution to the peri-implant bone. ${ }^{41}$ This finding is contradictory to the present study, in which there was less stress generated in the bone by the CFR-PEEK implants under oblique loading as compared toTi implants. The reason for this difference in findings may be that Endolign ${ }^{\circledR}$ CFR-PEEK was used in the present study. Endolign is a CFR-PEEK material that has $60 \%$ endless carbon fibers of parallel orientation. The modulus of elasticity of this material, as provided by manufacturers, is $150 \mathrm{GPa}$, which is higher than that of $\mathrm{Ti}(110 \mathrm{GPa})$ and 30\% CFR-PEEK (18 GPa). This provides stability with better stress distribution. ${ }^{30}$ A similar result was obtained by Schwitalla et al. in their study which compared the biomechanical behavior of $\mathrm{Ti}$, powder-filled PEEK and Endolign as implant materials. ${ }^{30}$ Powder-filled PEEK showed higher von Mises stress values with maximum deformation, while $\mathrm{Ti}$ and Endolign showed similar stress distribution. ${ }^{30}$

Researchers have assessed the outcome of using various prosthesis materials on stress distribution in the peripheral bone and implants, and suggested that a change in the prosthesis material brought no considerable difference in stress patterns. ${ }^{42-45}$ This corresponds with the present study, with different occlusal materials generating similar stress in the implants. The PEEK crown in the present study generated similar stress with both the CFR-PEEK and $\mathrm{Ti}$ abutments.

Tekin et al. assessed the stress created within the abutment and suggested that there was more stress when changing the abutment material than when changing the crown material. ${ }^{16}$ Kaleli et al. found that customized zirconia abutments had higher stress values as compared to customized PEEK abutments. ${ }^{5}$ Customized PEEK abutments had a 60 times lower modulus of elasticity than customized zirconia, and demonstrated less stress in the abutment and more stress in the crown. ${ }^{46} \mathrm{~A}$ similar result was obtained in the present study, in which there was less stress within the abutment and bone, and more stress in the crowns in the CFR-PEEK implant-abutment group.
This result may be due to the use of the CFR-PEEK material, which has a higher modulus of elasticity than $\mathrm{Ti}$, which reduces stress in the bone while having more stress within the CFR-PEEK implant.

In a FEA study by Ahmed et al., Ti implants-abutments under vertical loading generated high stress in the abutment and less stress in the bone. ${ }^{47}$ Stress distribution on the occlusal aspect was similar among different occlusal materials. The model with the porcelain crown received the highest von Mises stress value (345.390 MPa), while the model with the PEEK crown received the lowest von Mises stress value $(313.094 \mathrm{MPa}){ }^{47}$ In the present study, the opposite result was obtained; the model with the PEEK crown had more stress as compared to the PFM crown. The zirconia crown model received the highest von Mises stress value, while the PEEK crown model received a lower von Mises stress value. The reason behind this difference may be due to the modulus of elasticity of zirconia, which made this material more impervious to distortion.

Tekin et al. found less stress with the use of the PEEK abutment with the PFM crown under oblique loading. ${ }^{16}$ A similar result was found in the present study, with the CFR-PEEK implant-abutment with different restorative crowns. The reason may be that in this case, the abutment and implant were made of the CFR-PEEK material, which has a high modulus of elasticity $(150 \mathrm{GPa})$. In accordance with the energy dissipation theory, when the force applied to the implant-retained crown dissipates through the implant, as a result of elastic deformation, minimal energy is kept by the implant due to small alterations in the energy conservation feature of rigid implants. ${ }^{48}$

In the study by Tekin et al., it was observed that maximum stress was concentrated on the margins of the crown under oblique loading. ${ }^{16}$ Groups with Ti abutments had less stress in the crown as compared to groups with PEEK abutments. ${ }^{16}$ The present study showed the opposite result; both the CFR-PEEK and Ti implant groups with different crowns had similar von Mises stress values, and stress was concentrated on the margins of the crowns. The exception was the acrylic resin crowns, which had stress concentrated in the central fossa region.

The stress result of PEEK as a crown material was assessed in this study, and it has shown promising results as a crown material over both the CFR-PEEK and Ti abutments. Carbon fiber-reinforced polyetheretherketone showed good results when used as an abutment and implant, and the results were similar to the Ti implant and abutment with different restorative crowns.

\section{Conclusions}

In this FEA study, the amount of stress generated within the bone in the case of the CFR-PEEK implants with different restorative crowns was smaller in comparison with the Ti implants in oblique loading. This could be 
beneficial in terms of reducing lateral stress on implants and could help reduce crestal bone loss. The CFR-PEEK material may emerge as an alternative implant material in the near future and will certainly be beneficial for patients with hypersensitivity and allergic reactions to Ti. Further in vivo research should be conducted with PEEK crowns over CFR-PEEK implants-abutments to assess the osseointegration of this material and how this property can be further improved.

\section{ORCID iDs}

Swapnil Kumar Tamrakar (1) https://orcid.org/0000-0001-8279-5166 Sunil Kumar Mishra (1) https://orcid.org/0000-0003-4844-1844 Ramesh Chowdhary (1) https://orcid.org/0000-0002-3254-741X Srinivas Rao (1) https://orcid.org/0000-0003-0879-5330

\section{References}

1. da Silva-Neto JP, Pimentel MJ, das Neves FD, Xediec Consani RL, Fernandez dos Santos MB. Stress analysis of different configurations of 3 implants to support a fixed prosthesis in an edentulous jaw. Braz Oral Res.2014;28(1):1-7. doi:10.1590/S1806-83242013005000028

2. Abou-Obaid Al, Al-Otaibi HN, Akeel RF. Effect of single off-axis implant placement on abutment screw stability under lateral loading. Int $J$ Oral Maxillofac Implants. 2016;31(3):520-526. doi:10.11607/jomi.4124

3. Guarnieri R, Di Nardo D, Gaimari G, Miccoli G, Testarelli L. Short vs. standard laser-microgrooved implants supporting single and splinted crowns: A prospective study with 3 years follow-up. $J$ Prosthodont. 2019;28(2):e771-e779. doi:10.1111/jopr.12959

4. Giannobile WV. Getting to the root of dental implant tissue engineering. J Clin Periodontol. 2010;37(8):747-749. doi:10.1111/j.1600051X.2010.01589.X

5. Kaleli N, Sarac D, Külünk S, Öztürk Ö. Effect of different restorative crown and customized abutment materials on stress distribution in single implants and peripheral bone: A three-dimensional finite element analysis study. J Prosthet Dent. 2018;119(3):437-445. doi:10.1016/j.prosdent.2017.03.008

6. Misch CE. Dental Implant Prosthetics. $2^{\text {nd }}$ ed. St. Louis, USA: Mosby/ Elsevier Health Sciences; 2005:1-229.

7. Brånemark PI, Zarb GA, Albrektsson T. Tissue-Integrated Prostheses: Osseointegration in Clinical Dentistry. Chicago, USA: Quintessence Publishing;1985:88-98.

8. Hosoki M, Nishigawa K, Miyamoto $Y$, Ohe G, Matsuka Y. Allergic contact dermatitis caused by titanium screws and dental implants. J Prosthodont Res. 2016;60(3):213-219. doi:10.1016/j.jpor.2015.12.004

9. Kim KT, Eo MY, Nguyen TTH, Kim SM. General review of titanium toxicity. Int J Implant Dent. 2019;5:10. doi:10.1186/s40729-019-0162-x

10. Goutam M, Giriyapura C, Mishra SK, Gupta S. Titanium allergy: A literature review. Indian J Dermatol. 2014;59(6):630. doi:10.4103/0019-5154.143526

11. Niinomi M, Liu Y, Nakai M, Liu H, Li H. Biomedical titanium alloys with Young's moduli close to that of cortical bone. Regen Biomater. 2016;3(3):173-185. doi:10.1093/rb/rbw016

12. Friedrich RE, Todorovic $M$, Krüll A. Simulation of scattering effects of irradiation on surroundings using the example of titanium dental implants: A Monte Carlo approach. Anticancer Res. 2010;30(5):1727-1730.

13. Osman RB, Swain MV. A critical review of dental implant materials with an emphasis on titanium versus zirconia. Materials (Basel). 2015;8(3):932-958. doi:10.3390/ma8030932

14. Osman RB, Ma S, Duncan W, De Silva RK, Siddiqi A, Swain MV. Fractured zirconia implants and related implant designs: Scanning electron microscopy analysis. Clin Oral Implants Res. 2013;24(5):592-597. doi:10.1111/j.1600-0501.2011.02411.x

15. Sarot JR, Milani Contar CM, Cabral da Cruz AC, de Souza Magini R. Evaluation of the stress distribution in CFR-PEEK dental implants by the three-dimensional finite element method. J Mater Sci Mater Med. 2010;21(7):2079-2085. doi:10.1007/s10856-010-4084-7
16. Tekin S, Değer Y, Demirci F. Evaluation of the use of PEEK material in implant-supported fixed restorations by finite element analysis. Niger JClin Pract. 2019;22(9):1252-1258. doi:10.4103/njcp.njcp_144_19

17. Mishra S, Chowdhary R. PEEK materials as an alternative to titanium in dental implants: A systematic review. Clin Implant Dent Relat Res. 2019;21(1):208-222. doi:10.1111/cid.12706

18. Katzer A, Marquardt H, Westendorf J, Wening JV, von Foerster G. Polyetheretherketone - cytotoxicity and mutagenicity in vitro. Biomaterials. 2002;23(8):1749-1759. doi:10.1016/s0142-9612(01)00300-3

19. Jockisch KA, Brown SA, Bauer TW, Merritt K. Biological response to chopped-carbon-fiber-reinforced peek. J Biomed Mater Res. 1992;26(2):133-146. doi:10.1002/jbm.820260202

20. Wenz LM, Merritt K, Brown SA, Moet A, Steffee AD. In vitro biocompatibility of polyetheretherketone and polysulfone composites. J Biomed Mater Res. 1990;24(2):207-215. doi:10.1002/jbm.820240207

21. Chethan H, Krishna PD, Deepmala S, Rakshith H. Implant restoration materials: An overview. Int J Oral Implantol Clin Res. 2010;1(1):43-48.

22. Geng JP, Tan KB, Liu GR. Application of finite element analysis in implant dentistry: A review of the literature. J Prosthet Dent. 2001;85(6):585-598. doi:10.1067/mpr.2001.115251

23. Sagomonyants KB, Jarman-Smith ML, Devine JN, Aronow MS, Gronowicz GA. The in vitro response of human osteoblasts to polyetheretherketone(PEEK) substrates compared to commercially pure titanium. Biomaterials. 2008;29(11):1563-1572. doi:10.1016/j.biomaterials.2007.12.001

24. Chang Y, Tambe AA, Maeda Y, Wada M, Gonda T. Finite element analysis of dental implants with validation: To what extent can we expect the model to predict biological phenomena? A literature review and proposal for classification of a validation process. Int J Implant Dent. 2018;4(1):7. doi:10.1186/s40729-018-0119-5

25. Singh P, Wang C, Ajmera DH, Xiao SS, Song J, Lin Z. Biomechanical effects of novel osteotomy on mandibular expansion: A threedimensional finite element analysis. J Oral Maxillofac Surg. 2016;74(8):1658.e1-1658.e15. doi:10.1016/j.joms.2016.04.006

26. Liu S, Tang C, Yu J, Dai W, Bao Y, Hu D. The effect of platform switching on stress distribution in implants and periimplant bone studied by nonlinear finite element analysis. J Prosthet Dent. 2014;112(5):1111-1118. doi: 10.1016/j.prosdent.2014.04.017

27. Rosenstiel SF, Land MF, Fujimoto J. Principles of tooth preparation. In: Rosenstiel SF, Land MF, Fujimoto J. Contemporary Fixed Prosthodontics. $4^{\text {th }}$ ed. St. Louis, USA: Mosby/Elsevier Health Sciences; 2012:131-140.

28. Bagheri R. Film thickness and flow properties of resin-based cements at different temperatures. J Dent (Shiraz). 2013;14(2):57-63.

29. Sevimay M, Turhan F, Kiliçarslan MA, Eskitasçioglu G. Threedimensional finite element analysis of the effect of different bone quality on stress distribution in an implant-supported crown.J Prosthet Dent. 2005;93(3):227-234. doi:10.1016/j.prosdent.2004.12.019

30. Schwitalla AD, Abou-Emara M, Spintig T, Lackmann J, Müller WD. Finite element analysis of the biomechanical effects of PEEK dental implants on the peri-implant bone. J Biomech. 2015;48(1):1-7. doi:10.1016/j.jbiomech.2014.11.017

31. Akkayan B. An in vitro study evaluating the effect of ferrule length on fracture resistance of endodontically treated teeth restored with fiber-reinforced and zirconia dowel systems. J Prosthet Dent. 2004;92(2):155-162. doi:10.1016/j.prosdent.2004.04.027

32. Sannino G, Gloria F, Ottria L, Barlattani A. Influence of finish line in the distribution of stress through an all ceramic implant-supported crown: A 3D finite element analysis. Oral Implantol (Rome). 2009;2(2):14-27.

33. El-Zawahry MM, El-Ragi AA, El-Anwar MI, Ibraheem EM. The biomechanical effect of different denture base materials on the articular disc in complete denture wearers: A finite element analysis. Open Access Maced J Med Sci. 2015;3(3):455-461. doi:10.3889/oamjms.2015.074

34. Suansuwan N, Swain MV. Determination of elastic properties of metal alloys and dental porcelains. J Oral Rehabil. 2001;28(2):133-139. doi:10.1046/j.1365-2842.2001.00642.x

35. Zarone F, Sorrentino R, Apicella D, et al. Evaluation of the biomechanical behavior of maxillary central incisors restored by means of endocrowns compared to a natural tooth: A 3D static linear finite element analysis. Dent Mater. 2006;22(11):1035-1044. doi:10.1016/j.dental.2005.11.034 
36. de Faria Almeida DA, Pellizzer EP, Verri FR, Santiago JF Jr., Perri de Carvalho PS. Influence of tapered and external hexagon connections on bone stresses around tilted dental implants: Three-dimensional finite element method with statistical analysis. J Periodontol. 2014;85(2):261-269. doi:10.1902/jop.2013.120713

37. El-Anwar MI, El-Zawahry MM. A three dimensional finite element study on dental implant design. J Genet Eng Biotechnol. 2011;9:77-82. doi:10.1016/j.jgeb.2011.05.007

38. DeTolla DH, Andreana S, Patra A, Buhite R, Comella B. The role of the finite element model in dental implants. J Oral Implantol. 2000;26(2):77-81. doi:10.1563/1548-1336(2000)026<0077:TROTFE >2.3.CO;2

39. Akça $K$, Iplikçioglu $H$. Finite element stress analysis of the effect of short implant usage in place of cantilever extensions in mandibular posterior edentulism. J Oral Rehabil. 2002;29(4):350-356. doi:10.1046/j.1365-2842.2002.00872.x

40. Ferriera Koyama Takahashi JM, Dayrell AC, Xediek Consani RL, de Arruda Nóbilo MA, Pessanha Henriques GE, Mesquita MF. Stress evaluation of implant-abutment connections under different loading conditions: A 3D finite element study. J Oral Implantol. 2015;41(2):133-137. doi:10.1563/AAID-JOI-D-11-00205

41. Bataineh $\mathrm{K}, \mathrm{Al}$ Janaideh $\mathrm{M}$. Effect of different biocompatible implant materials on the mechanical stability of dental implants under excessive oblique load. Clin Implant Dent Relat Res. 2019;21(6):1206-1217. doi:10.1111/cid.12858

42. Sertgöz A. Finite element analysis study of the effect of superstruc ture material on stress distribution in an implant-supported fixed prosthesis. Int J Prosthodont. 1997;10(1):19-27.

43. Stegaroiu R, Kusakari H, Nishiyama S, Miyakawa O. Influence of prosthesis material on stress distribution in bone and implant: A 3-dimensional finite element analysis. Int J Oral Maxillofac Implants. 1998;13(6):781-790.

44. Wang TM, Leu LJ, Wang J, Lin LD. Effects of prosthesis materials and prosthesis splinting on peri-implant bone stress around implants in poor-quality bone: A numeric analysis. Int J Oral Maxillofac Implants. 2002;17(2):231-237.

45. Bassit $R$, Lindsröm $H$, Rangert $B$. In vivo registration of force development with ceramic and acrylic resin occlusal materials on implant-supported prostheses. Int J Oral Maxillofac Implants. 2002;17(1):17-23.

46. Rahmitasari F, Ishida Y, Kurahashi K, Matsuda T, Watanabe M, Ichikawa T. PEEK with reinforced materials and modifications for dental implant applications. Dent J (Basel). 2017;5(4):35. doi:10.3390/dj5040035

47. Ahmed SAS, Eldosoky MAA, El- Wakad MT, Agamy EMTM. Effect of stiffness of single implant supported crowns on the resultant stresses. A finite element analysis. Egypt J Hosp Med. 2016;63(1):172-184. doi:10.12816/0023843

48. Sheets CG, Earthmann JC. Natural tooth intrusion and reversal in implant-assisted prosthesis: Evidence of and a hypothesis for the occurrence. J Prosthet Dent. 1993;70(6):513-520. doi:10.1016/0022$-3913(93) 90265-p$ 